\title{
LAS MARCAS DE ORALIDAD EN LA NOVELA GRÁFICA ARRUGAS (ANÁLISIS DE SU TRADUCCIÓN AL ITALIANO)
}

\author{
Rosa María Rodríguez Abella \\ rosa.rodriguez@univr.it \\ Universidad de Verona (Italia)
}

\section{Resumen}

En España, como es sabido, Arrugas ha cosechado un sorprendente éxito de crítica y público, tanto entre los lectores habituales de cómics como entre los no tradicionales. En estas líneas, a través de una serie de ejemplos extraídos de la novela, analizaremos las soluciones adoptadas por la traductora, Alessandra Papa, para resolver las dificultades que esta situación comunicativa híbrida plantea en la lengua meta.

\begin{abstract}
"The marks of orality in the graphic novel Arrugas (Analysis of the Italian translation)" As everyone knows, Arrugas has achieved a surprising success in Spain. Critics and the general public alike have applauded the work and it has become popular amongst both regular and non-regular readers of comics. Through a series of examples taken from the novel, the current article analyzes the solutions which Alessandra Papa, the Italian translator, adopted in order to solve the difficulties this hybrid communicative situation poses in the target language.
\end{abstract}

Palabras clave: Traductología. Traducción subordinada. Marcas de oralidad. Cómic. Método traductor.

Keywords: Translation studies. Subordinate translation. Marks of orality. Comic book. Method of translation.

Manuscript received on March16, 2015 and accepted for publication on September $18,2015$. 



\section{Introducción}

Paco Roca obtiene en 2008 el Premio Nacional del Cómic por su novela gráfica Arrugas (noviembre de 2007). En la narración, donde se aborda la experiencia del alzhéimer, se combinan diferentes lenguajes, signos de carácter lingüístico y de tipo icónico o plástico ${ }^{1}$. De hecho, el relato avanza a través de las imágenes y del lenguaje verbal presente en el interior de los globos o bocadillos, las voces en off y las onomatopeyas que a menudo invaden las imágenes².

En cuanto a la narración verbal, como subraya Zanettin (1998: 1), esta "è [...] inserita in un contesto visivo che esercita una forte influenza sulle scelte traduttive". Por otra parte, el marco en el que se inserta este género textual impone una serie de limitaciones que determinan que se suela englobar la traducción de este tipo de textos bajo la etiqueta de 'traducción subordinada' (Mayoral Asensio, Kelly \& Gallardo 1986). Porque, a pesar de que "i due codici espressivi, parole e immagini, convergono a formare un linguaggio unitario" (Zanettin 1998: 1), en realidad, el traductor puede manipular exclusivamente el código verbal. Por lo tanto, es evidente que este tendrá que adecuar en todo momento la traducción a los vínculos impuestos por el código icónico33.

\section{Cómic, novel gráfica y oralidad}

Tratar de analizar el cómic, ya sea como lenguaje, ya sea como medio de comunicación de masas, comporta no pocas dificultades. Así, pues, aún no disponemos, a día de hoy, de una definición consensuada sobre el mismo. Con todo, desde nuestro punto de vista, uno de los acercamientos más

1. Según Barbieri (2010: 229), el cómic es "un medium al tempo stesso figurativo e narrativo", dado que "alla composizione del significato delle immagini del fumetto concorrono componenti sia narrative che non narrative". El crítico añade también que "non è possibile rendere conto degli effetti di senso delle immagini se si esclude l'una o l'altra".

2. Para una detallada caracterización del espacio reservado al lenguaje verbal, véase Gasca \& Gubern (2011).

3. Sobre las dificultades que entraña la traducción del género cómic, remitimos a los exhaustivos trabajos de Rota (2001), Carreras i Goicoechea, Flores Acuña \& Provezza (2008), Zanettin (2008) y Podeur (2012). 
esclarecedores a la problemática del cómic es el que propone el dibujante francés Bernard Duc (1982: 6):

Il y a bien des façons de définir une bande dessinée... Celui-ci vous dira que c'est un 'moyen de communication de masse', associant étroitement l'image et le langage, et c'est vrai. Un spécialiste des arts graphiques affirmera qu'il s'agit plutôt d'un genre de littérature dessinée, et c'est encore vrai. Mais un autre soutiendra que la bande dessinée est au fond plus proche du cinéma que de la littérature, et c'est une définition qui ne manque pas non plus de vérité.

S'il est difficile de définir avec précision la bande dessinée, c'est qu'elle se situe précisément au carrefour de plusieurs moyens d'expression artistique: l'art graphique, l'art cinématographique et la littérature. Elle est tout à la fois dessin, cinéma, écriture, se conjuguant entre eux pour former un art nouveau, doté d'un ensemble de moyens d'expressions extrêmement complet et varié $[\ldots]$.

En líneas generales, la mayoría de estudiosos (Ramírez Domínguez 1975; Rodríguez Diéguez 1977; Baur 1978; Muñoz Zielinski 1982) se muestran de acuerdo en reconocer que el lenguaje del cómic se caracteriza, primariamente, por la profunda interrelación entre código icónico y código verbal. No obstante, algunos teóricos (Coma 1979; McCloud 2005; Groensteen 2012) defienden la preeminencia de lo visual sobre lo verbal. Y, en efecto, existen ejemplos de cómics mudos o sin palabras, piénsese, por ejemplo, en Arzach (1975) de Moebius o el más reciente 3 segundos (2012) de Marc-Antoine Mathieu. Aunque no cabe duda de que las posibilidades narrativas de las viñetas mudas son muy limitadas. En realidad, lo normal es que al igual que ocurre en la realidad, ambos lenguajes se colijan en perfecta sinergia para transmitir el mensaje, porque:

qualsiasi immagine è polisemica, così come può esserlo l'elemento verbale, $\mathrm{e}$ proprio nell'interazione l'ambiguità viene risolta a favore di una delle possibili interpretazioni. Inoltre l'immagine, di per sé statica, acquista spessore temporale grazie alle parole nel balloon e nelle eventuali didascalie. Allo stesso modo è attraverso le parole che le immagini si uniscono in un continuum logico e viene reso comprensibile lo svolgimento dell'azione (Morgana 2003: 166) ${ }^{4}$.

Ciertamente la indisolubilidad en el papel impreso entre texto e imagen, además de ser uno de los rasgos caracterizadores de este género híbrido, puede ser también fuente de conflicto a la hora de afrontar la traslación de este tipo de textos, aunque, en realidad, el cómic no hace más que reproducir dos aspectos fundamentales de la comunicación humana: la emisión oral y la percepción visiva de la situación comunicativa (Morgana 2003: 166).

4. Esta autora pone de manifiesto también que el cómic es un medium dinámico, en evolución, y que su lenguaje está en constante interacción con otros lenguajes. 
En otro orden de cosas, pasando ahora a la denominación "novela gráfica', como señala García (2010: 269), esta etiqueta se erige en "un término de acuerdo -o de desacuerdo- para identificar un cómic adulto en oposición al tebeo tradicional"6. Según García (2011: 258), novela gráfica es el nombre que el gran público utiliza para distinguir:

un cómic contemporáneo, adulto y artístico que ha llegado de muy diversas fuentes y a través de corrientes diversas [...]. Obras muy diversas pero agrupadas por un sentimiento de diferenciación frente al cómic industrial producto de tradiciones inmemoriales de géneros, personajes, temáticas juveniles y dominio de los editores profesionales. El formato novela gráfica -es decir, el libro, más parecido al volumen de literatura convencional que al álbum de cómic clásico- ha sido el cauce preferente para este tipo de cómic, y el soporte que le ha permitido escapar de la librería especializada y el quiosco, donde no podía crecer, en dirección a la librería general ${ }^{7}$.

Efectivamente, en el panorama editorial actual parece haberse consolidado el empleo de este sintagma, 'novela gráfica', para referirse a una serie de obras de tema muy variado que se caracterizan, sobre todo, por su libertad y ambición creadora $^{8}$. Es más, incluso el propio Paco Roca reivindica el uso de este término para referirse a algunas de sus obras. Así, en una entrevista con motivo de la publicación de su novela El invierno del dibujante (2010), álbum en el que narra el abandono de la editorial Bruguera por cinco de sus dibujantes estrella para fundar la revista Tío Vivo, Roca comenta:

el medio sigue siendo el mismo, pero las palabras "historieta", "cómic" y "novela gráfica" marcan las fronteras. Ellos hacían historietas infantiles, no se planteaban hacer algo que no fuera interesante para un niño. El cómic ya llega a otro público porque habla de terror, de ciencia ficción, de sexo... Y luego surge la novela gráfica, que supone la libertad total para hacer lo que quieras y como quieras, sin limitaciones. Básicamente nos separa la ambición (citado en Barrios 2010: 5).

5. Como apunta García (2010: 33), fue en el año 1978 cuando la expresión 'novela gráfica' apareció por primera vez adornando la portada de Contrato con Dios, de Will Eisner. En líneas generales, la mayoría de los estudiosos coinciden en destacar que la novela gráfica se caracteriza por ser una única historia, normalmente compleja y de mediana extensión.

6. De hecho, la primera acepción de la voz tebeo en el DRAE es: "(De TBO, nombre de una revista española fundada en 1917). 1. m. Revista infantil de historietas cuyo asunto se desarrolla en series de dibujos".

7. Para una caracterización del género novela gráfica, remitimos al exhaustivo estudio de Santiago García (2011).

8. Según Díaz de Guereñu (2014: 10-11), actualmente, el uso generalizado de la etiqueta 'novela gráfica' trata de distinguir "con un rótulo apropiado obras que parecen obviamente distintas de las designadas con las usuales hasta ahora", obras, como pone de relieve el crítico, que son indicativas de "un cambio radical en el uso del medio". 
Con todo, como afirma Ramírez (2010: 12), "la naturaleza del medio, que no se inserta fácilmente en la 'institución arte' ni tampoco en la de la literatura" hace que pese a haber alcanzado un desarrollo prodigioso aún hoy en día sea necesario reivindicar los "elevados valores estéticos y culturales del medio cómic" (Ramírez 2010: 12)9.

En cuanto a los rasgos prototípicos del considerado por muchos como el noveno arte, como es sabido, este se basa en una serie de convenciones semióticas que el lector habitual adquiere y aprende a descodificar fácilmente: iconografía, expresión literaria y técnicas narrativas ${ }^{10}$.

En las líneas que siguen focalizaremos nuestro análisis en la traslación de un aspecto de la expresión literaria, en concreto el de la oralidad fingida presente en los globos ${ }^{11}$, en la voz en off ${ }^{12}$ y en las onomatopeyas ${ }^{13}$.

Entendemos además que la denominación de 'oralidad fingida' u 'oralidad construida' "no designa un único fenómeno homogéneo, sino que cubre más bien una multitud y gran variedad de manifestaciones de lo oral en lo escrito" (Brumme 2008: 7). Es decir, que utiliza determinados recursos lingüísticos considerados típicamente orales: repeticiones, vacilaciones, reformulaciones, el empleo de vocativos, interjecciones, onomatopeyas, ideófonos, etc., con el objetivo de evocar la autenticidad y naturalidad del lenguaje hablado.

9. Para Eco (1973: 155), el cómic presenta características estilísticas precisas y se erige además en un género literario "autonomo, dotato di propri elementi strutturali, di una tecnica comunicativa originale, fondata sull'esistenza di un codice condiviso dai lettori e a cui l'autore si rifà per articolare, secondo leggi formative inedite, un messaggio che si rivolge, insieme, all'intelligenza, all'immaginazione, al gusto dei propri lettori".

10. Entre los elementos propios de la 'grammatica del fumetto', Morgana (2012) destaca: "la forma della vignetta e del balloon, le didascalie, il lettering, le onomatopee (in inglese, spesso parole provviste di significato, come gulp, sigh, crash), la punteggiatura emotiva e autonoma dal testo scritto (passata nelle scritture giovanili e informali), le metafore visualizzate, i segni cinetici ecc".

11. Esto es, en los "recipientes simbólicos o contenedores que encapsulan los diálogos de los personajes parlantes representados en la viñeta, cuya procedencia se indica mediante un rabo o delta invertido dirigido al emisor de la locución inscrita" (Gasca \& Gubern 2011: 279).

12. Como señalan Gasca \& Gubern (2011: 377), la voz en off en los cómics se utiliza "en forma de locuciones de personajes que no vemos, porque se hallan supuestamente ubicados fuera de la delimitación territorial señalizada por los bordes de la viñeta, o supuestamente ocultos al lector por algún objeto, como las puertas o los biombos".

13. Otro aspecto importante es también el de la rotulación, porque no cabe duda de que "el tratamiento gráfico de los textos literarios [...] puede aportar decisivas connotaciones al sentido del texto" (Gasca \& Gubern 2011: 319). Para un análisis exhaustivo de las convenciones semióticas del cómic, véase Gasca \& Gubern (2011). 


\section{Las marcas de oralidad en Arrugas y su traducción al italiano}

Arrugas es una novela gráfica producida originalmente para el mercado francés, exactamente para la editorial Delcourt, donde se publica en marzo de 2007 con el título de Rides. Como el propio Roca explica en una entrevista (García 2008: 62), el hecho de publicar en Francia le obligó a hacer algunos cambios formales para acercar la obra al gusto de sus editores:

es cierto que el mercado francés te exige ciertas cosas. Incluso tuve que afrancesar algunas páginas para que el editor estuviese contento. Por ejemplo, cuando Emilio tiene el flashback y vuelve al aula donde estudió de niño, en la versión española había un crucifijo y un mapa de Europa. Me dijeron que el crucifijo lo quitase, porque Francia era laica desde hacía mucho tiempo, y que el mapa de Europa tal vez podría cambiarlo por uno francés. Cambié eso, cambié el menú de nochevieja (sic) para que fuese un menú de nochevieja (sic) típico francés, y los horarios de la residencia. Pero es la mentalidad francesa. En España a ningún editor se le ocurriría decirle a un autor francés que cambie ese tipo de cosas.

Aparte de estas pequeñas modificaciones, por lo demás, tanto el guión de Arrugas, como el resto, Roca lo escribe en español. Después, una vez terminada la novela, con los diálogos ya metidos en los globos de texto, la obra se tradujo al francés ${ }^{14}$. El álbum se editará posteriormente también en España, en noviembre de 2007, en la editorial Astiberri ${ }^{15}$. En Italia verá la luz en 2008 gracias a la editorial Tunué donde se publica bajo el título de Rughe.

El proyecto, como el propio Roca revela en el álbum Emotional World Tour (Gallardo \& Roca 2009: 22), surge de una serie de experiencias personales. El primer acontecimiento que desencadenó el deseo de realizar una historia sobre la vejez fue el constatar que sus padres se estaban haciendo mayores. El afán por comprender a sus progenitores lleva a Roca a interrogarse sobre "qué sienten, qué esperan de la vida, la soledad que tienen" (Roca 2012) las personas al envejecer ${ }^{16}$.

El segundo episodio se produce al comprobar una realidad social, "la gente no quiere ver ancianos en la publicidad" (Gallardo \& Roca 2009: 23).

14. Información proporcionada por el autor en mensaje electrónico (07/02/2015).

15. En 2008, Paco Roca gana el Premio Nacional de Cómic por esta obra. Posteriormente, en 2012, la novela es llevada al cine, logrando dos premios Goya: Mejor Filme de Animación y Mejor Guión Adaptado.

16. En la entrevista concedida a www.valenciaplaza.com (20/01/2012), el autor señala también: "a partir de ahí, pensé en hacer un cómic sobre las residencias de ancianos, y empecé a documentarme, a hablar con médicos, enfermeros y con gente que tenía a familiares en residencias". 
De ahí nace también el deseo por parte del autor "de comprender una etapa de la vida, la vejez, a la que la sociedad tiene bastante fobia" (Roca 2013a: 177) ${ }^{17}$.

Y, por último, el dibujante señala que "al hablar sobre la vejez era inevitable tratar una enfermedad como el Alzheimer (sic)" (Roca 2013a: 177), porque Emilio, el padre de su buen amigo MacDiego, tenía alzhéimer y pudo ver "cómo la enfermedad deteriora implacablemente al enfermo y cómo es también devastadora con los familiares que lo cuidan" (Roca 2013a: 177-178).

Todas estas vivencias confluyen de forma armónica en Arrugas. Es más, según Díaz de Guereñu (2013: 105), lo que incita a la lectura y a la relectura de la obra es "su fuerza, su capacidad para afectar al lector, para conmoverlo y moverlo a reflexión; en definitiva, su valor artístico". El crítico subraya también que esta es una obra "llamada a perdurar, que apuesta sin titubeos por la capacidad expresiva del cómic y que la agranda con algunos recursos de singular elocuencia" (2013: 105).

Entre los más interesantes, sin duda, el hecho de que Roca prescinda de la voz narrativa. Al respecto, el dibujante afirma: "quería que se comprendiera a los personajes por sus gestos, para que el lector se implicase más en la historia" (Azpitarte 2009: 162). Así pues, el autor muestra "lo que viven sus personajes y evita toda tentación de comentarlo" (Díaz de Guereñu 2013: 110). La elisión de la voz narrativa determina de hecho que a lo largo de las páginas de Arrugas no encontremos ni un solo cartucho con texto escrito ${ }^{18}$.

Otro recurso muy sugerente es el hábil aprovechamiento de "la dimensión gráfica del cómic para abrir una ventana a las mentes de sus personajes" (Díaz de Guereñu 2013: 115). En efecto, a menudo el relato se adentra en la mente de alguno de los personajes para que el lector comparta sus fantasías y sentimientos (Díaz de Guereñu 2013: 114) ${ }^{19}$. Por ejemplo, en esta página (Fig.

17. Roca comenta asimismo que la elección se debe en parte a que ha podido constatar que "la vejez es un tema que apenas ha sido tratado de una forma directa, no sólo en los cómics, sino tampoco en la literatura o en el cine" (Azpitarte 2009: 158).

18. Los cartuchos son "las cápsulas insertas dentro de la viñeta o entre dos viñetas consecutivas [...] cuyo texto inscrito cumple las funciones de aclarar o explicar el contenido de la imagen o de la acción, facilitar o completar su continuidad narrativa, o reproducir el comentario del narrador virtual. Como puede observarse sus funciones son tan amplias como las que Roland Barthes denominó anclaje (para desvanecer mediante palabras la polisemia o ambigüedad de una imagen) y conmutación (cuando el mensaje lingüístico complementa las imágenes, para hacer avanzar la narración)" (Gasca \& Gubern 2011: 273).

19. Díaz de Guereñu (2013: 115) pone el ejemplo que presentamos en la Fig. 1, esto es, cómo mediante un juego de plano y contraplano el dibujante nos devuelve a la infancia de Emilio y al pánico que sintió su primer día de colegio, pero a lo largo de la obra 
$1)^{20}$, donde se nos narra el ingreso de Emilio, un director de banco jubilado con claros síntomas de alzhéimer, en una residencia de ancianos, sin recurrir
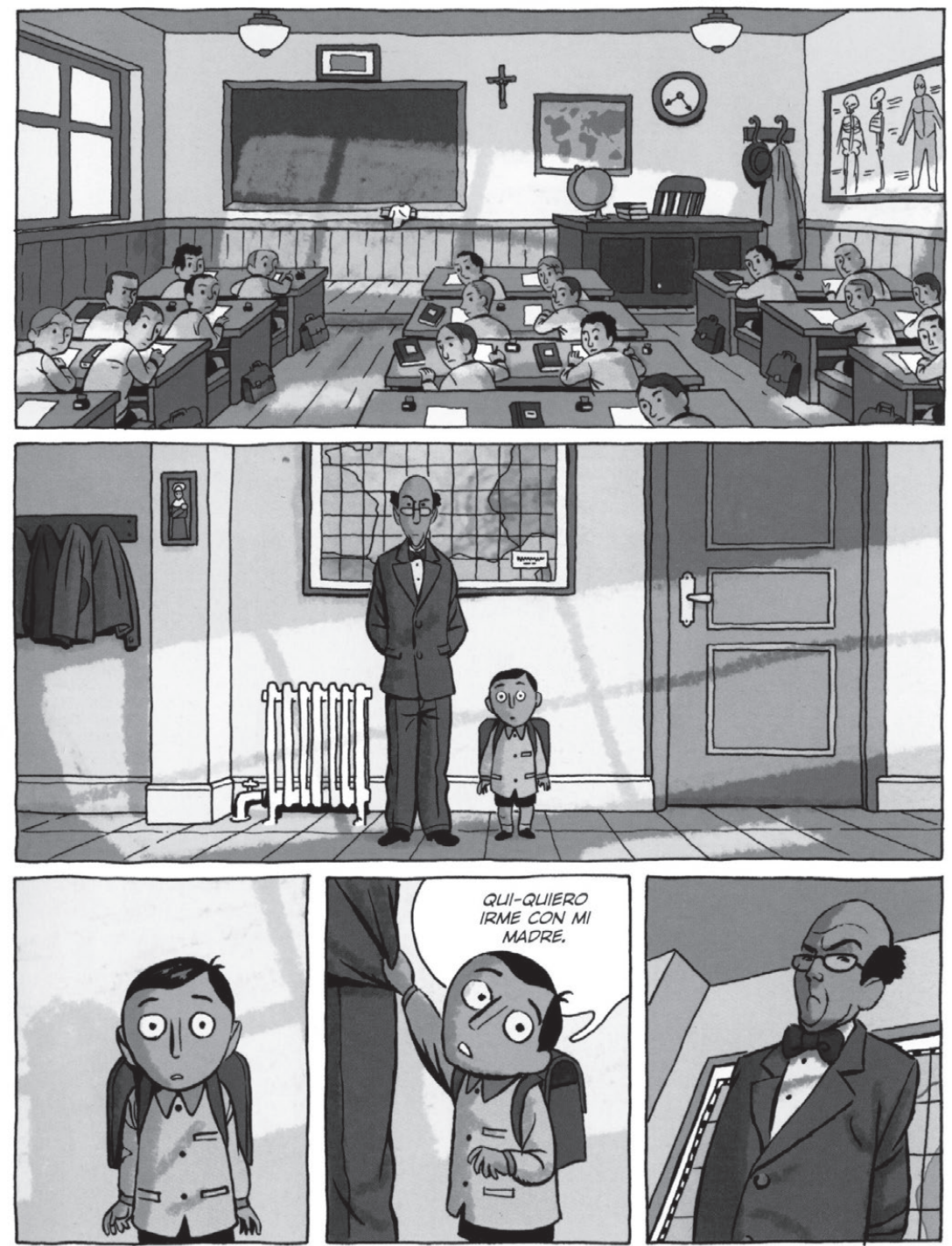

Figura 1

asistimos también a las imágenes mentales de otros personajes como las de la señora Rosario (2013: 18), las de Carmencita (2013: 44), etc.

20. El copyright de las diferentes imágenes corresponde al autor y editoriales pertinentes. Su uso es meramente informativo, con fines docentes y de investigación. 
a un cartucho de texto narrativo, el autor logra que el protagonista, al evocar su primer día de escuela, nos transmita esa sensación de nudo en el estómago que uno tiene cuando llega por primera vez a un lugar (Azpitarte 2009: 165) ${ }^{21}$.

Con todo, como señalábamos ya al principio de este trabajo, lo normal es que el código verbal y el icónico conformen un lenguaje unitario. Efectivamente, el magnífico engaste entre texto e imagen se puede apreciar también en la siguiente viñeta, donde el lector contempla ahora cómo tras la despedida, Emilio, acongojado e impotente, murmura como insulto dirigido a su vástago el adjetivo vulgar 'gilipollas' (Roca 2013a: 13), término del que se hará eco también Juan, antiguo locutor que ahora solo repite lo que oye ${ }^{22}$.

En la viñeta, la 'complicidad sígnica' (Morgana 2003: 167) con los lectores permite poner de manifiesto la entonación del protagonista. De tal manera que este rasgo prosódico, el de un enunciado murmurado, se concretiza mediante un tamaño de letra más pequeño del adjetivo vulgar que sale del globo de Emilio.
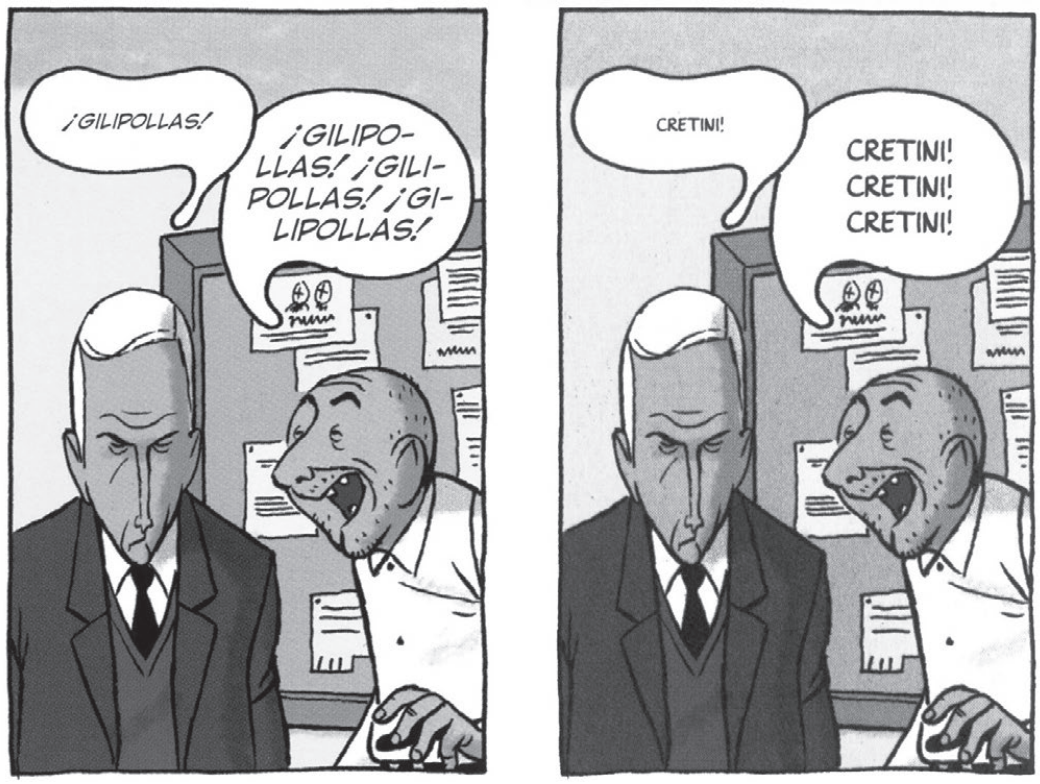

Figura 2

21. Sobre esta manera diferente de narrar, el propio Roca declara que cree que el éxito de Arrugas "ha abierto los ojos a mucha gente acerca de las posibilidades de un medio como el cómic a la hora de narrar historias de otro tipo" (Azpitarte 2009: 169).

22. No obstante, Silvia Morgana (2012) sostiene que "a parlare, con apparente ossimoro, sono però prevalentemente le immagini, in genere caratterizzate da forte denotatività e informatività". 
Se trata, como es sabido, de una convención semiótica propia del género que en este caso es utilizada para reflejar el estado emocional del protagonista. Resulta evidente además que el autor ha seleccionado un registro deliberadamente vulgar que, hasta cierto punto, contrasta con la personalidad del protagonista, justamente para mostrar mejor la rabia y frustración del personaje. Sin embargo, en el texto meta, la traductora opta por el vocablo cretini (Roca 2013b: 9), rompiendo el tono del discurso del texto origen. Además, no cabe duda de que el vocablo italiano cretino no recoge todos los matices de expresividad del término 'gilipollas' ${ }^{23}$.

Otras veces, el código verbal es utilizado de manera ingeniosa para "suscitar una experiencia lectora próxima al desconcierto del anciano con Alzheimer (sic)" (Díaz de Guereñu 2013: 115). Por ejemplo, durante los ejercicios de movilidad la monitora propone pasar la pelota al revés (2013a: 30-31) es decir, al compañero que está a la izquierda. En este caso (Fig. 3), el dibujante altera las convenciones del género ${ }^{24} \mathrm{y}$, de hecho, subvierte las expectativas del lector, de manera que lo que lee el lector no es el diálogo real de los personajes "sino la versión confusa que percibe el protagonista" (Díaz de Guereñu 2013: 115). Desafortunadamente, en el TM no se recoge este original hallazgo expresivo del autor, pues el término 'talope', forma alterada de 'pelota', es corregido y trasladado por palla (2013b: 26-27), perdiéndose por completo la ambivalencia del original.

Observamos también que en el TO el código verbal se acomoda perfectamente a los diferentes contextos de comunicación. Sin duda, uno de los ejemplos más significativos tiene lugar cuando el protagonista, tras descubrir casualmente por un error del enfermero que tiene alzhéimer (Roca 2013a: 55), visita al médico del geriátrico (2013a: 56-58). En este caso, el diálogo es utilizado por el dibujante para introducir elementos nuevos en el plano conceptual sobre esta enfermedad, por ejemplo: diagnóstico, cuadro clínico, tratamiento, etc. En el diálogo, especialmente dramático, de tres páginas que tiene lugar entre el doctor y Emilio, dado que la función perseguida es la de informar a un paciente sobre las características de la enfermedad que sufre, comprobamos cómo el especialista aborda su materia de especialidad

23. De acuerdo con Beinhauer (1991: 56), el término 'gilipollas' indica un "idiota que se comporta como un cobarde y un tonto".

24. Efectivamente, como subraya Eco (1973: 150), el elemento fundamental de la semántica del cómic es "anzitutto il segno convenzionale della 'nuvoletta' (che è appunto il 'fumetto', lo 'echtoplasme', il 'balloon') il quale, se tratteggiato secondo alcune convenzioni, e terminante in una lama che indica il viso del parlante, significa 'discorso espresso". 

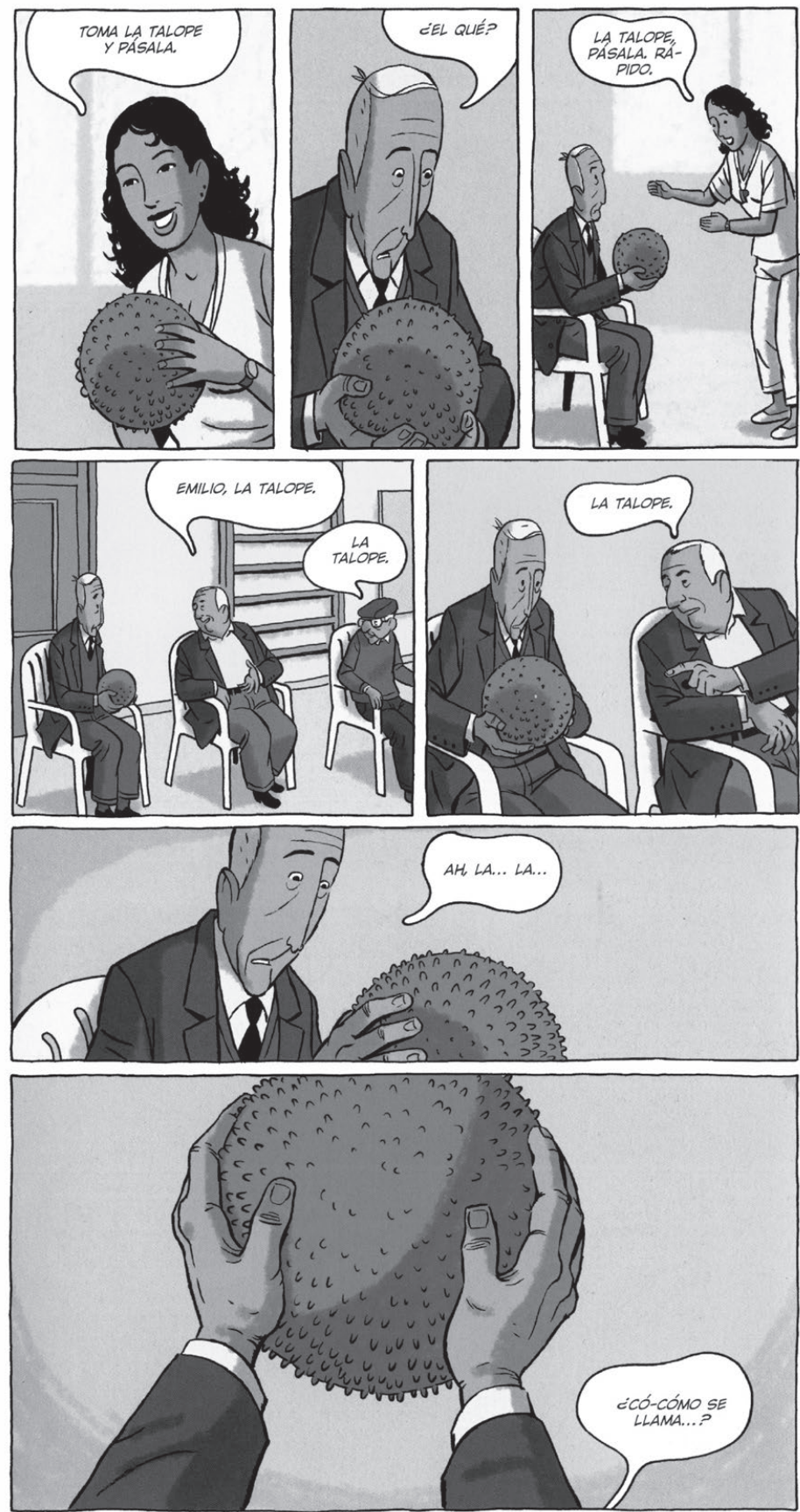

Figura 3 
adaptando su expresión a la situación comunicativa. Nos hallamos, por tanto, frente a un discurso especializado de tipo divulgativo enfocado hacia el público general, esto es, los lectores de la novela y el propio Emilio ${ }^{25}$. Como se puede comprobar en las viñetas que presentamos a continuación a modo de ejemplo (Fig. 4), una de las características más destacadas en esta situación comunicativa es, sin duda, la exactitud en la expresión por parte del doctor.
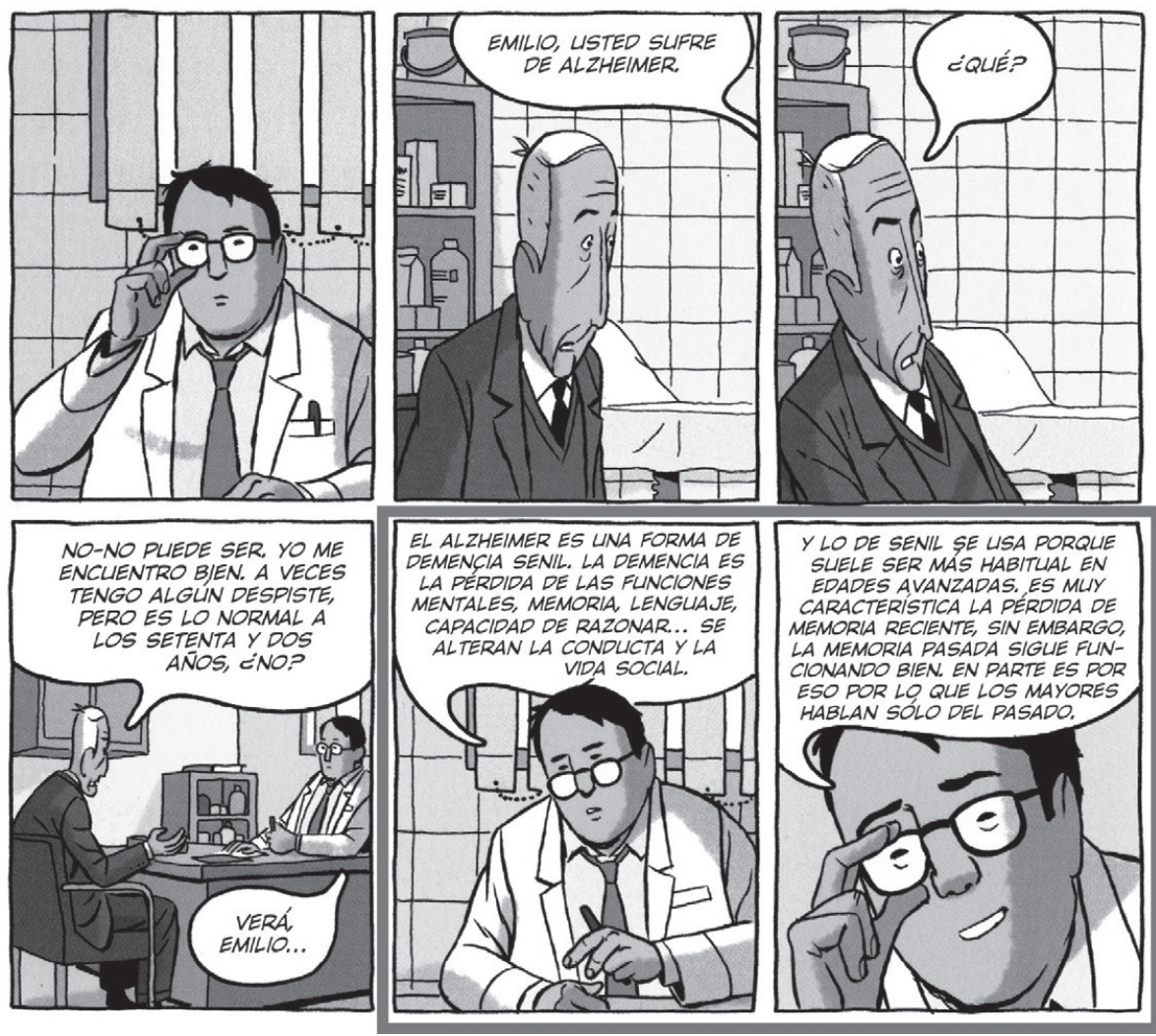

Figura 4

En el TM (2013b: 52), en cambio, se altera la modalidad lingüística presente en el TO (2013a: 56) y no se respetan las estructuras conceptuales del

25. En resumen, uno de los interlocutores es un especialista en el ámbito conceptual abordado, es decir, pertenece a un grupo profesional específico. La situación comunicativa es de tipo informativo y el tono de la comunicación es formal. 
dominio, de hecho, se trivializa el conocimiento científico del doctor como se puede constatar en las dos viñetas que siguen (Fig. 5).

Así pues, pese a presentar el TO una situación de comunicación marcada, con la presencia de una terminología específica ('demencia senil', 'memoria reciente', 'memoria pasada', 'funciones mentales', etc.), por el contrario, en el TM se constata una total falta de precisión y ausencia de exactitud en la expresión con respecto al $\mathrm{TO}^{26}$.
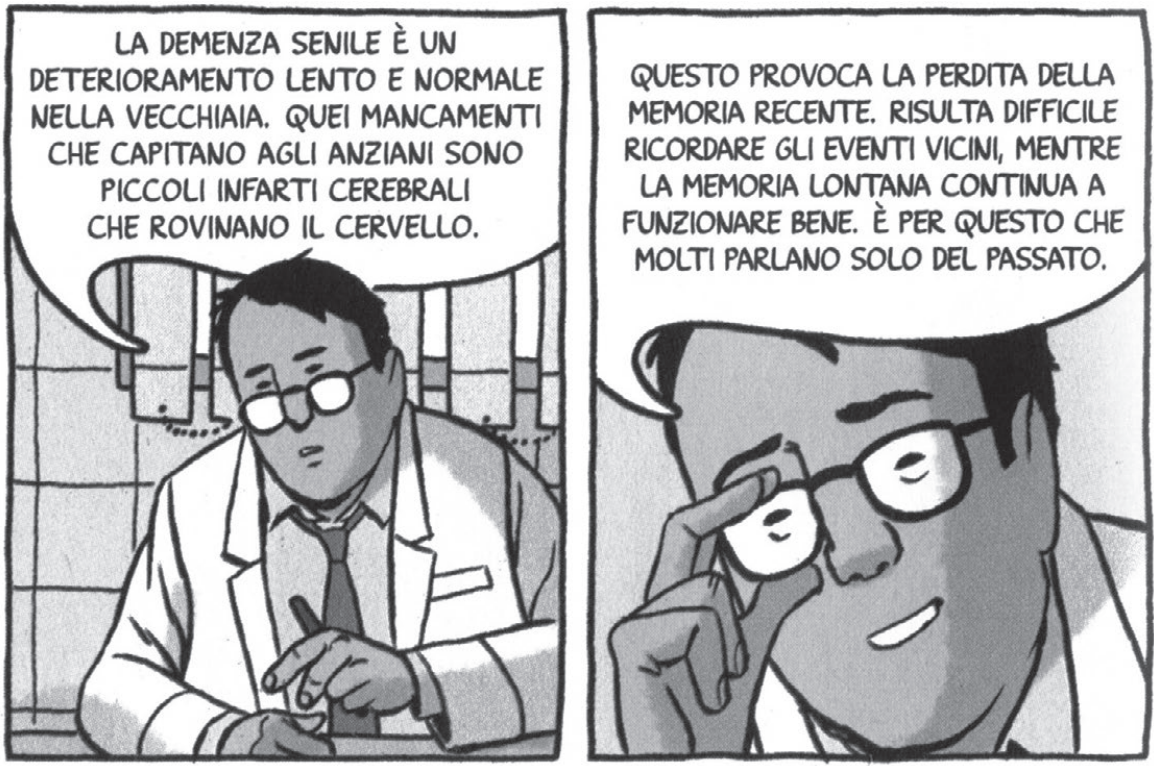

Figura 5

Otro rasgo característico del lenguaje hablado es, sin duda, el uso de los marcadores del discurso, en este caso se trata del marcador conversacional 'pues', uno de los marcadores más empleados en el español oral.

26. Sobre la longitud de este diálogo, Roca afirma que se preocupó realmente por saber si un doctor daría tantas explicaciones y comenta que, efectivamente, "los hay que creen que hay que explicar al paciente todo, sin secretos" (Azpitarte 2009: 162). 

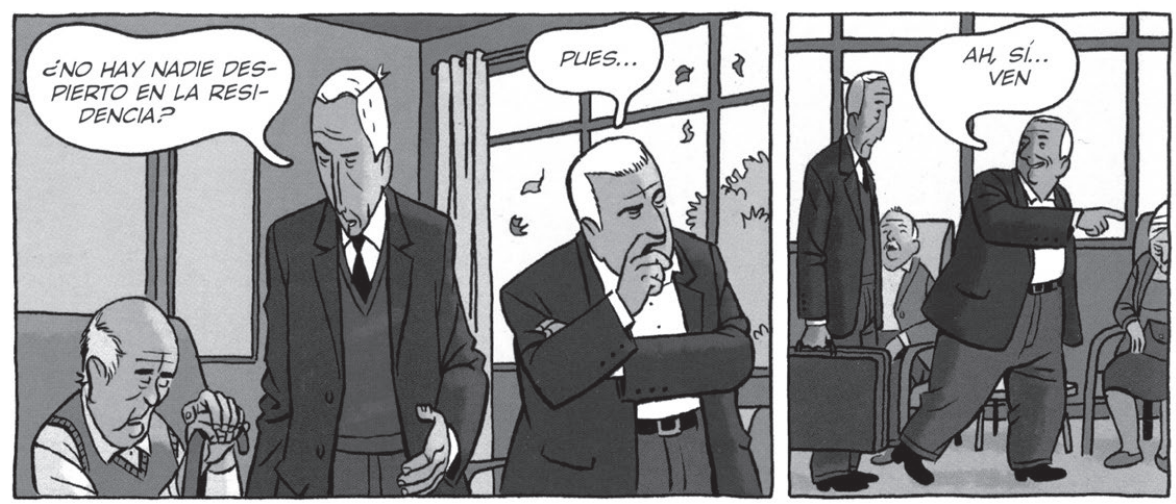

Figura 6

En esta viñeta (2013a: 18), el marcador polifuncional 'pues', seguido de entonación suspendida, es utilizado como inicio de intervención reactiva ante la pregunta de Emilio: “¿No hay nadie despierto en la residencia?”. El marcador actúa, por consiguiente, como enlace pregunta-respuesta expresando duda, vacilación ${ }^{27}$. Es más, la caracterización visiva que se nos da de Miguel, marcada por el gesto pensativo, así nos lo confirma. Efectivamente, parece como si el interlocutor, Miguel, se estuviera dando un tiempo para encontrar la respuesta a la pregunta de Emilio. En la traducción al italiano se opta por el equivalente funcional dunque (2013b: 14) ${ }^{28}$, que permite reflejar que el hablante está reorganizando sus ideas. Ahora bien, teniendo en cuenta la situación comunicativa, si se hubiera querido marcar el titubeo de Miguel, se hubiera podido mantener ese matiz en el TM mediante las partículas ehm o bien beh, que en italiano sirven para encubrir una vacilación del hablante.

27. Sobre los usos del marcador pues y su traducción al italiano, véase Calvi \& Mapelli (2004).

28. Se trata de una partícula que presenta, fundamentalmente un valor conclusivo y continuativo. De hecho, según Serianni (1999: 542), dunque permite señalar "una deduzione logica" o también expresar "una sintesi conclusiva di ciò che è stato detto in precedenza". 

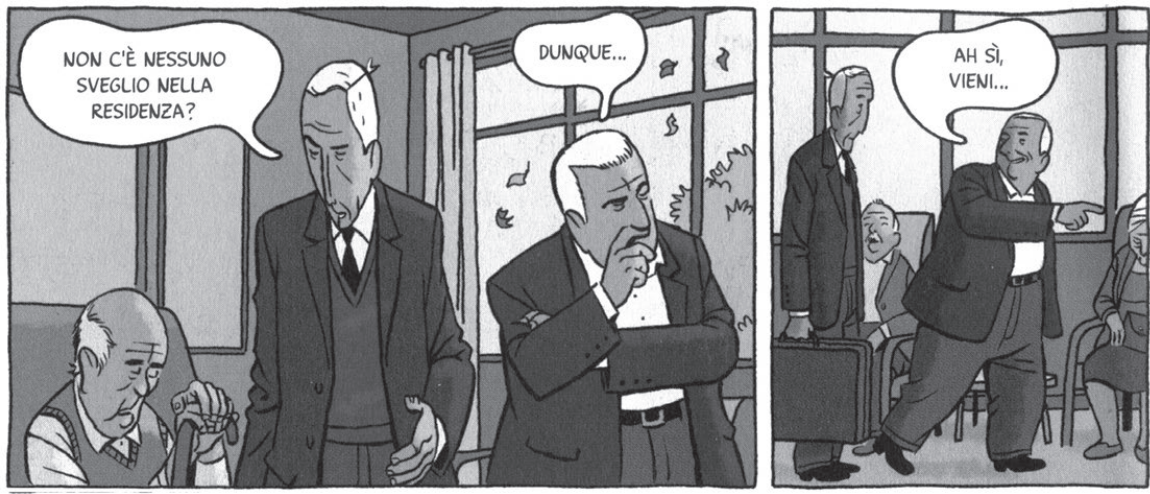

Figura 7

Para terminar, afrontaremos un elemento clave de la semántica del cómic, esto es, los signos gráficos utilizados para plasmar las onomatopeyas y las palabras expresivas (sustantivos y verbos fonosimbólicos) ${ }^{29}$. Además, hay que tener en cuenta que en Arrugas las onomatopeyas cumplen un papel muy importante en la historia. De hecho, el propio dibujante reconoce que ha tratado de utilizarlas también de modo creativo para resolver varias escenas difíciles ${ }^{30}$. En nuestro análisis y cotejo entre el TO y el TM hemos comprobado que las onomatopeyas y los fonosímbolos no se traducen nunca cuando invaden la imagen y sí cuando aparecen dentro de los globos, aunque en este caso se trata, sobre todo, de interjecciones ${ }^{31}$. Pero, como es sabido, incluso las onomatopeyas "per quanto più trasparenti, sono comunque legate alle specifiche culture in cui sorgono - come dimostrano le variazioni tra le diverse lingue" (Gheno 2003). Es decir, ante un mismo referente, cada lengua lexicaliza de

29. De acuerdo con Gasca \& Gubern (2009 \& 2011), no distinguiremos aquí entre palabras expresivas y onomatopeya, "en cuanto icono acústico [... ] que aspira a convertirse en traducción oral y/o escrita, de los ruidos" (2009: 8). Adoptaremos, por el contrario, un criterio ancho incluyendo en esta categoría no sólo las onomatopeyas puras sino también una serie de sustantivos y verbos que en el mundo del cómic se utilizan 'a modo' de onomatopeyas.

30. Por ejemplo, en dos escenas, "el sonido precede a los personajes y narra sin necesidad de que un texto de apoyo explique la historia" (Azpitarte 2009: 166). En concreto, cuando Emilio empieza a afeitarse de noche (Roca 2013a: 44) y cuando Miguel fuma un cigarro en la nieve (2013a: 53).

31. Por lo que se refiere a los fonosímbolos, téngase en cuenta también que el tamaño de sus letras, "tanto como su color (frío o cálido), sugieren su intensidad sonora, en un ejemplo singular de sinestesia óptico-acústica" (Gasca \& Gubern 2009: 9). 
manera distinta la onomatopeya correspondiente, de acuerdo con sus reglas fonológicas y grafemáticas.

En las viñetas que presentamos a continuación (Fig. 8) encontramos la representación acústica del aplauso, de hecho, como señalan Gasca \& Gubern (2009: 255), en los cómics del área hispanohablante, 'plas, plas' se utiliza para simbolizar "el sonido rítmico de los aplausos". En cambio, en italiano este sonido se transcribe de forma diferente, esto es, mediante clap, clap $^{32}$. Así pues, en este caso no existe correspondencia gráfica entre las dos lenguas, sin embargo, en el TM se opta por dejar la onomatopeya en la $\mathrm{LO}^{33}$. Desconocemos las razones de esta elección, aunque quizás se deba a la mayor permeabilidad de la lengua italiana a la penetración de préstamos crudos, sobre todo, provenientes del inglés.
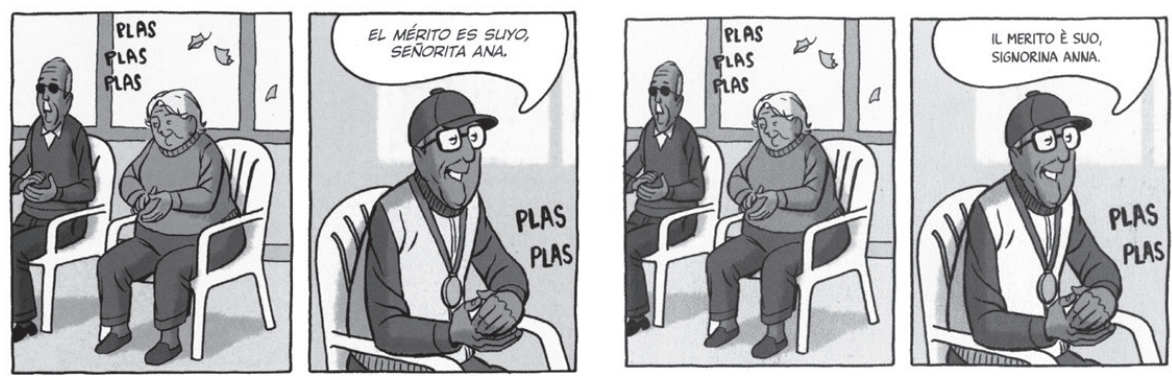

Figura 8

Lo mismo ocurre con otros fonosímbolos de uso disimétrico entre las dos lenguas $^{34}$, por ejemplo 'rasc, rasc' (2013a: 25), que acústicamente sugiere el sonido que se produce al frotar la piel con las uñas, tendría en italiano como forma equivalente grat, grat. También 'tap' (2013a: 29), que indica el ruido de un golpe, con frecuencia como efecto de una percusión. En cambio, en italiano, para este valor semántico de la viñeta en objeto, el sonido sería boing. Algo parecido sucede con 'chof chof chof' (2013a: 44), que en español indica el sonido que se produce al caminar sobre los charcos, también en este caso en

32. De hecho, en la segunda acepción del Treccani se señala: "clap ${ }^{2}$ 〈kläp〉 s. ingl. [dal v. (to) clap «battere le mani», di origine onomatopeica], usato in ital. come interiez. - Nel linguaggio dei fumetti, parola che riproduce (generalm. ripetuta: clap clap) il rumore prodotto da un applauso".

33. Para la traducción de las onomatopeyas al italiano hemos contado con la ayuda de Federico Brusco, ilustrador de cómics, a quien desde aquí damos las gracias por sus valiosos consejos y sugerencias.

34. Las onomatopeyas presentes en la Fig. 9 en el TM se hallan en las pp. 21, 25 y 40. Las dos onomatopeyas de la Fig. 10 en la página 59 del TM. 
el TM se mantiene la onomatopeya en español, aunque en italiano este sonido se transcribe por splash, splash.
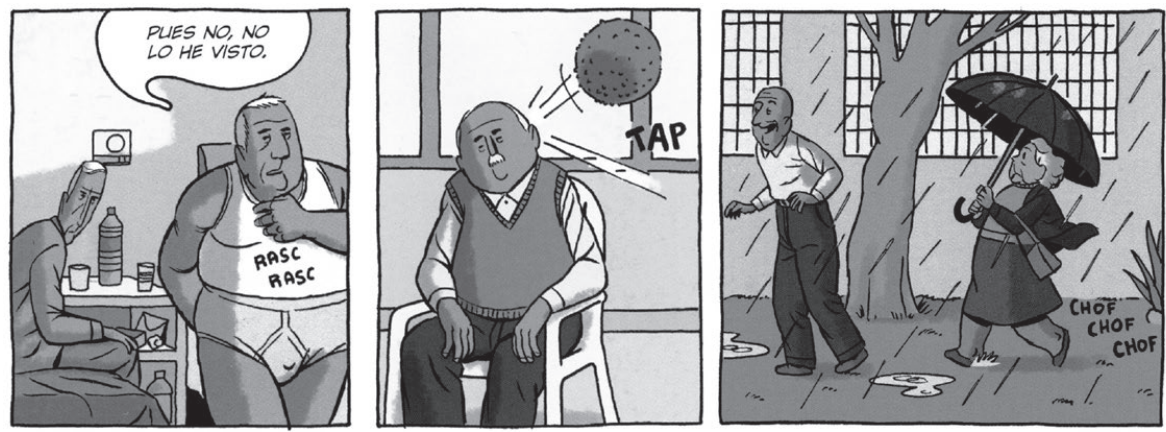

Figura 9

Tampoco 'tap' (2013a: 63), onomatopeya utilizada en el TO para indicar el ruido de un libro que se cierra de golpe, es trasladada a la lengua meta por la forma correspondiente, en este caso tump. También es divergente el uso de 'plaf' (2013a: 63), que en la viñeta denota el golpe de un libro, sonido que en italiano se transcribe mediante stump.
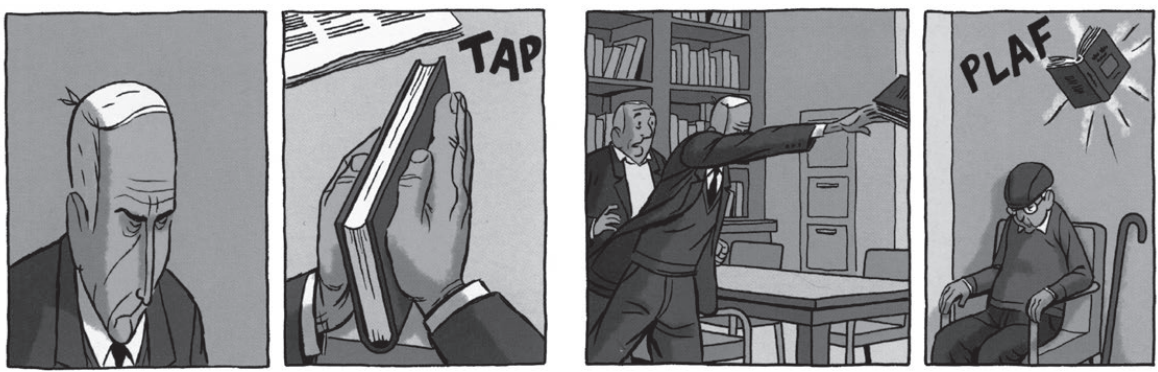

Figura 10

Aparte de lo ya expuesto, el cotejo de la traducción con el texto original ha evidenciado también que, a menudo, términos que no presentan ninguna dificultad traslativa, como por ejemplo el vocablo 'bocadillo' presente en la siguiente tira (2013a: 65), son trasladados recurriendo a técnicas no pertinentes en esa situación comunicativa. 

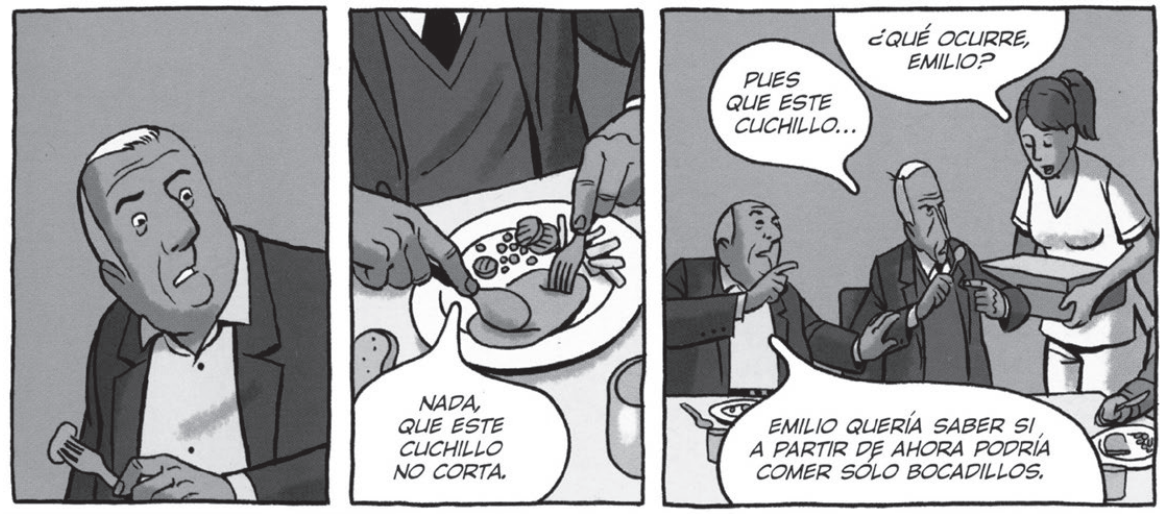

Figura 11

Como se puede comprobar, para trasladar este vocablo, en la tira en italiano se ha recurrido, innecesariamente, a la técnica de la creación discursiva ${ }^{35}$, pues, el término 'bocadillos' es traducido por bigné (2013b: 61), en castellano 'petisú' (según el DRAE, "pastelillo redondo hecho de masa, al horno, y relleno después con una crema dulce").
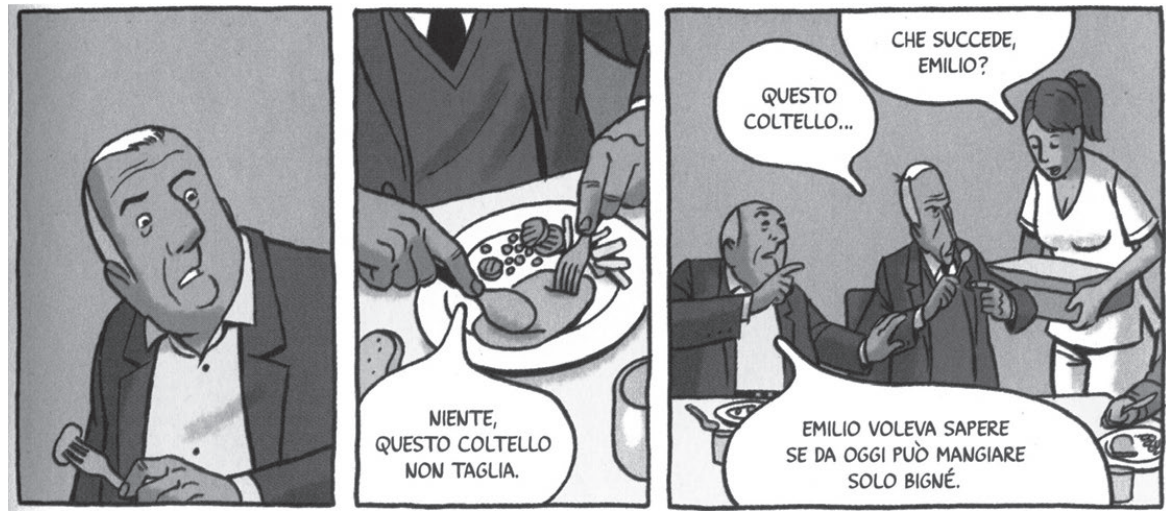

Figura 12

Se produce, claramente, una transposición errónea, sobre todo si tenemos en cuenta que la camarera ante la petición de Miguel contesta: "Preguntaré en la cocina. No creo que haya ningún problema" (2013a: 66). Sin duda, al lector

35. Esto es, utilizando una "equivalencia efímera, totalmente imprevisible fuera de contexto" (Hurtado Albir 2004: 270). 
del TM le resultará un tanto extraño que se acepte sin más que un anciano de un día para otro pase a comer solo 'petisús'.

La comparación textual nos ha permitido detectar también algunas discrepancias por lo que se refiere a la traslación de los nombre propios presentes en el original. En la actualidad, la tendencia es la de conservar los antropónimos y, efectivamente, en el TM la mayor parte se dejan en español: Miguel, Juan, Dolores, Modesto, Agustín, Esteban, Emilio, Félix, Martín, Josefa, Julia, Ramón; sin embargo, en cuatro casos se traducen al italiano: Rosaria, Anna, Sole y Carmelina y, en un caso, el del 'señor Pellicer', se recurre de nuevo a una equivalencia efímera y se traslada por Renato. Se verifica también una incongruencia entre elementos gráficos y narrativos al trasladar 'Menú de Nochebuena' (2013a: 54) por Menù di Natale (2013b: 50) ${ }^{36}$. Efectivamente, la escenografía presente en las diferentes viñetas es la propia de la cena de Nochebuena: velas, champán, gorros de Papá Noel, etc ${ }^{37}$.
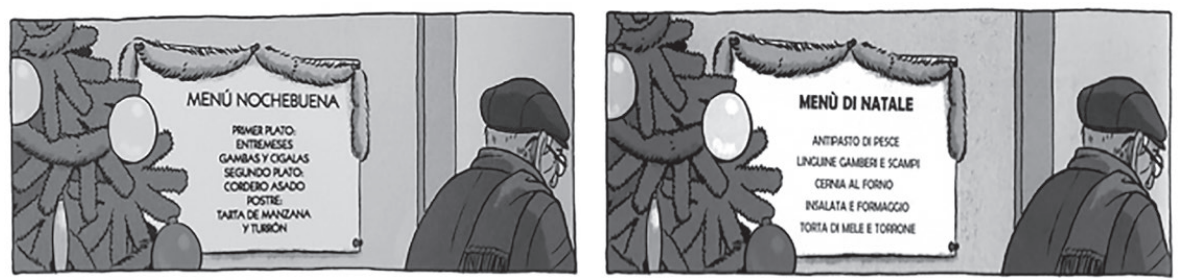

Figura 13

\section{A modo de conclusión}

En resumen, coincidimos con Podeur (2012: XI) cuando afirma que la novela gráfica es el dominio por excelencia para la experimentación, puesto que "les auteurs agissent en toute liberté pour un public adulte restreint désormais éduqué très tôt au verbo-iconique; un public que sait donc lire les différents

36. En España la Nochebuena, víspera del nacimiento de Jesús, se celebra cenando con la familia, comiendo dulces típicos navideños y cantando villancicos. En cuanto al día de Navidad, este normalmente se conmemora con una comida similar a la cena de Nochebuena. En Italia, dependiendo de las zonas, se prefiere festejar con la comida de Navidad (pranzo di Natale) o con la cena de Nochebuena. De cualquier manera, en el TM se hubiera podido evitar la incongruencia entre las imágenes de la cena y el rotulado del cartel trasladando 'Menú de Nochebuena' por Menù della Vigilia di Natale, o bien, Cenone della Vigilia di Natale.

37. Nótese también que los platos del menú, a excepción del postre, han sido sustituidos por otros más típicos de la cocina italiana, esto es, se ha recurrido a la técnica de la adaptación. 
strates de chaque cadre-case, et se montre de plus en plus exigeant" ${ }^{\prime 38}$. Es decir, es evidente que los lectores de novela gráfica están acostumbrados a una descodificación que podríamos denominar 'multiniveles'. En cierto modo, como pone de relieve Rota (2001: 6), traducir cómics significa "tradurre non solo un'opera straniera, ma anche un diverso modo di intendere il fumetto, di realizzarlo, di leggerlo". Así pues, uno de los retos que deberá afrontar el traductor será el de garantizar también a los lectores del TM esa original descodificación 'multiniveles'.

En líneas generales, hemos constatado que en la traducción al italiano de Arrugas se respeta el vínculo presente en el original entre el código icónico y el código lingüístico. No obstante, el análisis que hemos llevado a cabo refleja que, por ejemplo, en el caso de las onomatopeyas ese vínculo no siempre se mantiene idéntico. De hecho, a los lectores italianos puede sorprenderles la presencia de onomatopeyas extrañas a la cultura fumettistica italiana, pues, como hemos puesto de relieve, ambas lenguas difieren en la transcripción de muchos sonidos. Sin embargo, en el TM se opta por dejar las onomatopeyas en la LO, aunque no siempre las representaciones gráficas de los sonidos presentes en el TM se corresponden con los patrones tradicionales para el italiano $^{39}$. Además, hemos verificado que la mayoría de las onomatopeyas presentes en el TO son específicas del ámbito hispánico, como el propio Roca nos ha señalado en un correo electrónico: "hay onomatopeyas que están integradas en el dibujo, en general, todas las que están fuera de los globos de texto. [... ] Lo habitual es hacerlo en inglés para que sea universal, pero eso me incomoda un poco" $(26 / 11 / 2014)^{40}$.

En cuanto a las otras marcas de oralidad características de Arrugas (conectores pragmáticos, registro lingüístico, estilemas del autor, etc.), como ya hemos señalado, a menudo se eliminan o no se recogen los matices expresivos presentes en el TO.

En conclusión, no cabe duda de que en la novela gráfica la interrelación texto-imagen condiciona el trabajo del traductor, pero, no es menos cierto

38. Esta estudiosa señala también que el trabajo de un autor de novela gráfica no es un trabajo fácil porque: "il lui faut un scénario, la compétence d'un dessinateur, écrire pour être regardé, puis lu" (2012: XI).

39. En líneas generales, la lengua italiana utiliza muchas más onomatopeyas en inglés que el español.

40. Por otra parte, es notorio también que "las técnicas de impresión actuales permiten hacer cambios en la grafía tanto dentro del globo como fuera" (Muñoz-Calvo 2013: 120). Este dato nos ha sido confirmado también por el director editorial de Tunué, Massimiliano Clemente, en conversación telefónica (26/11/2014). 
también que justamente la naturaleza de este género puede facilitar enormemente la labor del mismo y erigirse en instrumento de desambiguación textual.

\section{Referencias bibliográficas}

AzPitarte, Koldo. (2009) Senderos. Una retrospectiva de la obra de Paco Roca. Bilbao: Laukatu.

BARBIERI, Daniele. (2010) Il pensiero disegnato. Saggi sulla letteratura a fumetti europea. Roma: Coniglio Editore.

Barrios, Nuria. (2010) "La ambición del dibujante." El País (Babelia), 11 de diciembre de 2010, pp. 4-5.

BAUR, Elisabeth Katrin. (1978) La historieta: una experiencia didáctica. México: Nueva Imagen.

BEINHAUER, Werner. (1991) El español coloquial. Madrid: Gredos.

BRUMME, Jenny (ed.) (2008) La oralidad fingida: descripción y traducción. Teatro, cómic y medios audiovisuales. Madrid: Iberoamericana/Vervuert.

CALVI, Maria Vittoria \& Giovanna Mapelli. (2004) "Los marcadores "bueno", "pues", "en fin" en los diccionarios de español e italiano."Artifara: revista de lenguas y literaturas ibéricas y latinoamericanas 4. Versión electrónica: <http:// dialnet.unirioja.es/servlet/articulo? codigo=1202721>

Carreras i Goicoechea, María; Estefanía Flores Acuña \& Monica Provezza. (2008) La traducción de cómics. Corto Maltés, Lupo Alberto y Dylan Dog en español. Roma: Aracne.

ComA, Javier. (1979) Del gato Félix al gato Fritz: historia de los cómics. Barcelona: Gustavo Gili.

Díaz De Guereñu, José Manuel. (2013) "Relectura de Arrugas." En: Roca, Paco 2013a. Arrugas. Bilbao: Astiberri, pp.105-129.

Díaz de Guereñu, José Manuel. (2014) Hacia un cómic de autor (A propósito de Arrugas y otras novelas gráficas). Bilbao: Universidad de Deusto.

Duc, Bernard. (1982) L’Art de la BD: du scénario à la réalisation graphique. París: Glénat.

ECO, Umberto. (1973 [1965]) Apocalittici e integrati. Milán: Bompiani.

GALLARDO, Miguel \& Paco Roca. (2009) Emotional World Tour (diarios intinerantes). Bilbao: Astiberri.

García, Santiago. (2008) "Entrevista a Paco Roca: 'El cómic es muy apropiado para lo dramático'." $A B C$ ( $A B C D$, suplemento cultural), 6 de diciembre de 2008, pp. 62-63.

GARCÍA, Santiago. (2010) La novela gráfica. Bilbao: Astiberri.

GarCíA, Santiago. (2011) "En el umbral. El cómic español contemporáneo." ARBOR Ciencia, Pensamiento y Cultura 2 (Extra), pp. 255-263. 
GASCA Luis \& Román Gubern. (2011) El discurso del cómic. Madrid: Cátedra.

GASCA Luis \& Román Gubern. (2009 [2008]) Diccionario de onomatopeyas del cómic. Madrid: Cátedra.

GHENO, Vera. (2003) "L'onomatopea." En: Accademia della Crusca, sezione 'Consulenza linguistica'. Versión electrónica: <http://www.accademiadellacrusca.it/it/lingua-italiana/consulenza-linguistica/domande-risposte/ lonomatopea>

Groensteen, Thierry. (2012) Il sistema fumetto. Génova: ProGlo.

HurTado AlBiR, Amparo. (2004 [2001]) Traducción y traductología. Madrid: Cátedra.

Istituto DELla EnCiClopedia ItALIANA FONDATO DA GIOVANni TRECCANi. Vocabolario. Versión electrónica: <http://www.treccani.it/vocabolario/>

Mayoral Asensio, Roberto; Natividad Gallardo San Salvador \& Dorothy Kelly. (1986) "Concepto de traducción subordinada (cómic, cine, canción, publicidad): perspectivas no lingüísticas de la traducción.” En: Fernández, Francisco (ed.) 1986. Actas del III Congreso Nacional de Lingüística Aplicada. Valencia: Servicio de Publicaciones de la Universidad de Valencia, pp. 95-105.

McCloud, Scott. (2005) Entender el cómic: el arte invisible. Bilbao: Astiberri.

MorganA, Silvia. (2012) "Stabile, convenzionale, mimetico: il teatro del fumetto." En: Enciclopedia Treccani. Versión electrónica: <http://www.treccani.it/magazine/lingua_italiana/speciali/fumetti/Morgana.html>.

MorganA, Silvia. (2003) "La lingua del fumetto." En: Bonomi, Ilaria; Andrea Masini \& Silvia Morgana (eds.) 2003. La lingua italiana e i mass media. Roma: Carocci, pp. 165-198.

MUÑOz ZIELINSKI, Manuel. (1982) La bande dessinée (système de comunication, art plastique et recourse pédagogique). Madrid: Universidad Complutense de Madrid. Tesis doctoral.

Muñoz-CAlvo, Micaela. (2013) “¡AY!, ¡HUY!, ¡PAF!, ¡BOUM!, ¡ZAS!: Interjecciones, sonidos inarticulados y onomatopeyas en Astérix en Hispania y sus traducciones en las lenguas de la península ibérica." Transfer 8, pp. 117152. Versión electrónica: <http://www.raco.cat/index.php/Transfer/article/ view/269632>

Podeur, Josiane. (2012) Tradurre il fumetto - Traduire la bande dessinée. Nápoles: Liguori.

Ramírez Domínguez, Juan Antonio. (1975) El “cómic” femenino en España: arte sub y anulación. Madrid: Cuadernos para el Diálogo.

RAmírez DomíngueZ, Juan Antonio. (2010) "Prefacio. La novela gráfica y el arte adulto." En: García, Santiago 2010. La novela gráfica. Bilbao: Astiberri, pp. 11-13.

Real ACademia Española. (2014) Diccionario de la lengua española. Versión electrónica: <http://www.rae.es/recursos/diccionarios/drae> 
RocA, Paco. (2013a [2007]) Arrugas. Bilbao: Astiberri.

RocA, Paco. (2013b [2008]) Rughe. Traducción de Alessandra Papa. Latina: Tunué.

RocA, Paco. (2013c [2010]) El invierno del dibujante. Bilbao: Astiberri.

RODRÍGUEZ DIÉGUEZ, José Luis. (1977) Las funciones de la imagen en la enseñanza: semántica y didáctica. Barcelona: Gustavo Gili.

RotA, Valerio. (2001) Nuvole migranti. Viaggio nel fumetto tradotto. Mottola: Lilliput.

SERIANNI, Luca. (1999) Grammatica italiana. Italiano comune e lingua letteraria. Turín: UTET.

Valenciaplaza.COM. (2012) "Entrevista. Paco Roca: Arrugas es la antítesis del mundo de la publicidad." Versión electrónica: <http://www.valenciaplaza.com/ ver/46496/-paco-roca----arrugas--es-la-antitesis-del-mundo-de-lapublicidad.html>

ZANETTIN, Federico. (1998) "Fumetti e traduzione multimediale." IntTRAlinea 1. Versión electrónica: <http://www.intralinea.org/archive/article/Fumetti_e_ traduzione_multimediale>

Zanettin, Federico. (2008) Comics in Translation. Londres: Routledge. 


\section{NOTA BIOGRÁFICA / BIONOTE}

Rosa María Rodríguez Abella es investigadora y Profesora Agregada de Lengua y Traducción en el Departamento de Lenguas y Literaturas Extranjeras de la Universidad de Verona. Licenciada en Filología, sección Filología Románica (Italiano) por la Universidad de Salamanca. Actualmente sus líneas de investigación se centran en la traducción literaria (Tratamiento de la cultura lingüística en la traducción al italiano de Asesinato en el Comité Central, 2013; La traducción de los elementos culturales en una novela de Vázquez Montalbán, 2012) y en las lenguas de especialidad, fundamentalmente en la lengua del turismo (Hacia una caracterización de la newsletter turística: el caso de Spain. info, 2015; Reflexiones en torno al género boletín digital turístico: situación comunicativa y análisis lingüístico, 2014; El discurso de la promoción turística institucional en Internet, 2013). Es miembro del grupo de investigación Linguaturismo de la Universidad de Milán.

Rosa María Rodríguez Abella is a researcher and Assistant Professor in Language and Translation at the Department of Foreign Languages and Literature at the University of Verona. She holds a degree in Philology, section of Romance Philology (Italian) from the University of Salamanca. Currently, her research is focused on literary translation (Tratamiento de la cultura lingüistica en la traducción al italiano de Asesinato en el Comité Central, 2013; La traducción de los elementos culturales en una novela de Vázquez Montalbán, 2012) and in specialty languages, primarily in the language of tourism (Hacia una caracterización de la newsletter turística: el caso de Spain.info, 2015; Reflexiones en torno al género boletín digital turístico: situación comunicativa y análisis lingüistico, 2014; El discurso de la promoción turística institucional en Internet, 2013). She is a member of the research group Linguaturismo of the University of Milan. 
